\title{
Quasi-Realism, Absolutism, and Judgment-Internal Correctness Conditions*
}

\author{
Gunnar Björnsson
}

\begin{abstract}
The traditional metaethical distinction between cognitivist absolutism, on the one hand, and speaker relativism or noncognitivism, on the other, seemed both clear and important. On the former view, moral judgments would be true or false independently on whose judgments they were, and moral disagreement might be settled by the facts. Not so on the latter views. But noncognitivists and relativists, following what Simon Blackburn has called a "quasi-realist" strategy, have come a long way in making sense of talk about truth of moral judgments and its independence of moral judges and their attitudes or standards. The success of this strategy would undermine the traditional way of understanding the distinction, and it is not obvious how it can be reformulated. In this paper, I outline the difficulty posed by quasi-realism, raise problems for some prior attempts to overcome it, and present my own suggestion, focusing on correctness conditions that are internal to the act of moral judgment.
\end{abstract}

\section{Some Traditional Distinctions, and Why They Seemed Important}

Metaethicists have traditionally distinguished between absolutist cognitivism (sometimes called "objectivism"), relativist cognitivism (often called "appraiser relativism"), and noncognitivism. Both the distinctions and their importance seemed clear enough.

First, if some form of cognitivism were correct, moral opinions and statements could be true or false, correct or incorrect. If noncognitivism were true, on the other hand, there would be no such correctness or in-

\footnotetext{
* Earlier versions of this paper were presented in 2007 at seminars at University of Gothenburg and Uppsala University, and at ETMP 2008. I thank the audiences on those occasions as well as Caj Strandberg, Ragnar Francén Olinder, Stephen Finley, and two anonymous referees for helpful comments. The topic of this paper seemed a good fit for the occasion, as Ingvar Johansson's manuscript Is Ought? from 1994 explores metaethical issues from an internal perspective in ways resembling quasirealist strategies.
} 
correctness and no truth or falsehood: only different moral opinions and different moral claims. Moreover, moral claims would not express propositions and would not be describing actions, characters or political institutions, and moral opinions would not be beliefs about, or representations of, states-of-affairs. Instead, they would be desires, or conative or emotive states of approval or disapproval, or commitments to act or not act in certain ways. Consequently, there could be no fact of the matter as to whether an act is morally wrong.

Second, if relativist cognitivism were true, then if one person thought that an act was morally wrong while another thought that it wasn't, they could both be correct, or both incorrect, if their judgments were made relative to different moral standards. And if they were, there would be no real disagreement about the facts: even if the two judgments shared the same character - the same function from contextually given standards to content or truth-conditions - they would have different truth-conditions. If absolutism were correct, on the other hand, the judgment that one person accepted and the other rejected would be subject to the same appraiser-independent standards of correctness. If one were correct, the other would be incorrect.

Given this map of the metaethical territories, it was quite clear why these distinctions mattered for normative ethics. My impression is that most normative ethicists have assumed some form of absolutist cognitivism, and it is easy to see why. On absolutism, there would be correct answers to the moral questions that are being asked and the answers one person suggests would be directly relevant to others who are thinking about the same question: if my answers are correct, they will be correct for others too, and vice versa. Consequently, there can be what I will call a "moral science": a collaborative enterprise aiming at the accumulation of correct answers to shared moral questions. Assuming the importance of correct moral beliefs, and assuming that answers to moral questions are not hopelessly beyond our ken, normative ethics would have a straightforward rationale.

Weak forms of relativism would also be capable of sustaining a moral science, although of a slightly parochial sort. These are the forms that lie closest to absolutism and take moral standards to be either widely shared - shared by most or all people in liberal societies, say - or quite similar although not strictly identical. But the stronger and more judge- 
dependent the relativism - the more it takes moral standards to vary widely from individual to individual - the more moral agreement and disagreement would have to be the kind of agreement or disagreement in attitude that noncognitivists say they are. There would be room for moral enquiry, but as versions of relativism approaches subjectivism, such inquiry would increasingly be a matter of finding out what the investigator herself likes or accepts. The collective aspect of moral science would be gone.

On noncognitivism, finally, there could be no moral science because there could be no correct or incorrect answers to moral questions. The room for systematic investigation into correct answers would be restricted to investigations concerning the non-moral assumptions on which some moral claims are based. Moreover, noncognitivists standardly think that in many cases, moral disagreements are fundamentally based on disagreements in attitude: in such cases, the way the world is wouldn't support one of these claims in favor of the other.

This is not to deny that both noncognitivism and strong relativism allow for a pursuit of a coherent system of attitudes or norms, or a mutual adjustment of attitudes through discussion of the sort that can help cooperation through the coordination of attitudes and expectations (Gibbard 1990; Lenman 2007). But, as traditionally understood, neither takes the content of our moral questions to determine any one correct answer independently of who is asking the question.

My concern here is with what I have just discussed: the straightforward consequences of the basic metaethical positions for the possibility of a moral science. Given this concern, the important distinction seems to be that between absolutist cognitivism and weak relativism, on the one hand, and noncognitivism and strong relativism, on the other: under the former, a moral science might be possible; not so under the latter. ${ }^{2}$

\footnotetext{
${ }^{1}$ The old distinctions were not always clear-cut. For example, since prescriptions seem incapable of truth or falsehood, prescriptivism is usually understood as a form of noncognitivism. But Richard Hare's (1981) form of prescriptivism took knowledge of the relevant non-moral facts to determine what the correct moral judgments would be and thus seems to leave room for a moral science.

${ }^{2}$ By contrast, the distinction between strong forms of relativism and noncognitivism doesn't matter for the possibility of a moral science: it is mostly stressed by people in the noncognitivist tradition (e.g. Horgan and Timmons 2004) who think that relativism is obviously false and that opponents of noncognitivism (e.g. Shafer-
} 
Admittedly, matters might be more complicated. Further information can give us reason to expect absolutism to have different consequences. Suppose, for example, that the only form of absolutism that has any chance of being true were one given which moral knowledge is outside our epistemic reach. Then absolutism would render moral science impossible. Or suppose that moral truths would lose all authority or normative force if we came to believe in some form of relativism or noncognitivism, however weak (Smith 1994:172, e.g.). Then the important distinction would seem to be that between absolutism and the other positions: weak relativism would not undermine moral science, but would undermine our interest in it almost as much as strong relativism and noncognitivism. To focus the discussion, however, I will ignore these complications, and take for granted that the traditional distinction that matters for a moral science is that between absolutism and weak relativism, on the one hand, and noncognitivism and strong relativism, on the other. The difficulty that I will be concerned with here is that this distinction has seemed to dissolve in light of work by people in the noncognitivist tradition: people have been at loss pinpointing the real difference between an absolutist cognitivist such as Russ Shafer-Landau and an heir of the noncognitivist tradition such as Allan Gibbard. If my way of explaining the distinction and deal with this difficulty is basically sound, complications can be added afterwards.

Landau 2003:33) tend to equate or conflate the two and therefore think that noncognitivism must also be false.

A number of interesting points about can be raised concerning the relation between relativism and noncognitivism. For a recent discussion of combinations of cognitivist and noncognitivist views, for example, see Ridge (2006a) and Schroeder (2009), for a defense of the distinction between relativism and expressivism, see Horgan and Timmons (2004), and for recent discussion of the relation between judgment and expression, see Joyce (2002), Ridge (2006c), and Schroeder (2008a).

A further complication is the introduction of assessor-relativism, according to which the truth-value of a judgment or claim is relative to circumstances of evaluation determined by the context of assessment. Applied to moral judgments, this view might imply that a moral judgment is true relative to my circumstances of evaluation, but not to yours. I ignore this complication, as the difference between assessor-relativism, noncognitivist expressivism and speaker relativism seems largely notational. (See e.g. Dreier 2009; Björnsson and Finlay 2010:24-5; Björnsson and Almér 2010:43 note 26, e.g.). 


\section{The Difficulty: Quasi-Realism and Quasi-Absolutism}

The difficulty I have in mind, and that I would like to circumvent, stems from the promise of what Simon Blackburn dubbed "quasi-realism". Under this banner, Blackburn and others have famously attempted to show how phenomena characteristic of paradigmatically absolutist cognitive thinking and discourse are just what we should expect given only make assumptions that noncognitivists would be happy to endorse. Such ambitions were part of the noncognitivist tradition in ethics from early on (Stevenson 1937; 1963:214-20; Hare 1970) but have been especially prominent in recent work by people such as Blackburn himself (1984, 1993, 1998), Mark Timmons (1999) and Allan Gibbard (1990, 2003), and I have contributed in small ways to this recent trend myself (Björnsson 2001, 2013; Björnsson and Finlay 2010).

Quasi-realism responds to what might be the major problem for noncognitivism: that it seems to go against the common sense understanding of moral thinking and discourse. No category mistake seems to be involved in saying that some moral claims are true or correct, or that some people believe that suicide is morally wrong, or that someone's conduct was described as morally objectionable. Moreover, moral predicates can figure in various unasserted contexts, just as ordinary descriptive predicates: in negated claims, questions, antecedents of conditionals, and in characterizations of objects of mental states such as fear or hope. Such embedded occurrences, it seems, would not be straightforwardly intelligible if moral claims were simply expressions of conative and noncognitive states of mind. Why, for example, would we make negative moral claims, expressing negative moral judgments, unless they rule out states-of-affairs represented by their positive counterparts? To make a negative judgment isn't just to not make, or event to refuse to make, the positive counterpart: the agnostic rejects both a claim and its negation. And why would we make conditional statements with moral antecedents if moral terms express desires rather than represent facts? Saying that it might be right to punish someone only if she has done something wrong seems to presuppose that it is a real matter of fact whether she has done something wrong, a fact that something can be conditional on. A further problem - shared by noncognitivists and relativists — is that it has seemed to many that when one person believes that an act is morally wrong and another believes that it isn't, then if one person is correct, the 
other must be wrong: they have a real disagreement about the correctness of the claim that the act is morally wrong.

Defenders of noncognitivism or relativism can reply in three ways to these problems. The first is to deny or qualify the alleged evidence. This might be most promising when it comes to intuitions about agreement and disagreement, where quite a few people - philosophers and laymen - deny that moral disagreement must be factual (but see Goodwin 2008). The second is to try explaining away the phenomena as based on widespread mistakes about moral thinking and discourse. But the third and probably most popular kind of reply is quasi-realism. It takes seemingly cognitivist or absolutist phenomena for granted and tries to show how they can be accommodated by noncognitivism. Various approaches have been attempted, but what follows, in brief outline, is one that I find comparatively plausible (Björnsson 2001, 2013; cf. Blackburn 1993, 1998; Gibbard 1990, 2003; Timmons 1999; Schroeder 2008).

First, let a thought be something that is formed in an act of judgment and can be subject to negation. Given the practical importance of the moral attitudes that noncognitivists take to constitute our basic moral thoughts, and the complexity of grounds on which such attitudes can be based, it makes sense that we should have a "faculty of judgment" governing such attitudes, letting us accept some attitudes - putting them in position to govern us in normal ways - while rejecting others - disqualifying them from so governing us (Björnsson 2001:90-93). ${ }^{1}$ Now understand the negation of a thought as the psychological item the function of which is to prevent a given thought from governing us, an item added to a thought when we make a negative judgment. Since we can suspend judgment - consider a thought and try on an attitude without either fully disqualifying it from or putting it in position to have its effects - it is possible for the agnostic to accept neither a thought nor its negation (Björnsson 2001:94; cf. Sinclair 2011).

Second, non-cognitivists can understand the application of predicates such as "correct", "wrong", "true" and "false" to moral thoughts and

\footnotetext{
${ }^{1}$ It is of course true that we can prevent the expressions of thoughts that we do accept, and allow expression of thoughts that we reject: perhaps we are acting, for example. But acceptance and rejection in judgment could be seen as what governs the sincere and spontaneous effects of our thoughts, rather than our play-acting. $\mathrm{Cf}$. Gibbard (1990: ch. 4).
} 
claims, building on the following two assumptions: (1) "True" and "false" attribute conformity to or violation of some fundamental standard for accepting or rejecting a thought, or for accepting or rejecting a syntactically declarative claim expressing such a thought. (2) "Correct" and "right" more generally attribute conformity to some relevant standard; "incorrect" and "wrong" attribute violation of such a standard. What the relevant standard is typically varies with the object of assessment: we say that a move in chess is correct, having in mind its adherence to the rules of the game, or say that a map correct, having in mind that its elements correspond to relevant elements in the are mapped. In applying any of these six predicates to ordinary representational thoughts, the relevant standard is that he world is at it is represented by the thought. In applying them to moral thoughts, however, non-cognitivists can say that we relate to whatever standards fundamentally govern our acts of moral judgment, i.e. the standards that ultimately determine whether we accept or reject the attitude constituting the moral thought under consideration (Björnsson 2013).

Third, it seems that in everyday parlance, to believe something just is to take it to be true, so noncognitivists can say that our thought that wanton cruelty is wrong is a belief insofar as we take it to accord with our standards for attitudes constituting such thoughts, i.e. insofar as we accept the thought, or are disposed to accept it, in an act of judgment. Relatedly, to describe something seems to be to say something about it that can be true or false. If so, we describe wanton cruelty when we say that it is wrong. Furthermore, it seems that something is a representation if it is the kind of thing that can be true or false. So beliefs or claims that wanton cruelty is morally wrong are representations. Similarly, we can say that our belief that wanton cruelty is wrong is true if and only if it corresponds to the facts in the sense that things are as it says they are, that is, if and only if wanton cruelty is wrong. Since we accept the claim that wanton cruelty is wrong, we can also say that it corresponds to the facts. (Cf. Dreier 2004.)

Fourth, since we typically assume that fundamental standards for accepting or rejecting moral thoughts have universal scope, applying to thoughts independently of whose thoughts they are, we will think that if one party of a moral disagreement is correct, the other is not (Björnsson 2013). Noncognitivists can explain the assumption of universal scope 
with reference to the general function of moral thinking and moral discourse, namely to coordinate attitudes: such coordination requires that attitudes satisfy the same standards, independently of whose attitudes they are.

Fifth, noncognitivists might say that to accept a conditional thought is to accept the consequent under supposition of the antecedent, thus making sense of conditional thoughts, such as the thought that if he didn't do anything wrong, he shouldn't be punished. To accept something under the supposition that someone didn't do anything wrong is to accept it while reasoning as if accepting the thought that he didn't do anything wrong, which on noncognitivism is to reason as if accepting a negative moral attitude towards what he did (Björnsson 2001).

Sixth, and finally, noncognitivists can deny that moral facts depend on our attitudes. For example, for me to accept that torture would have been right even if I had not disapproved of torture would be for me to accept that torture is right when reasoning as if accepting that I do not disapprove of torture. Since my grounds for accepting that torture is wrong make no reference to my disapproval of torture, but instead to its disrespect for and effects on the victim and society, such reasoning would not involve any changes in these grounds, and thus no changes in my judgment that torture is wrong (Blackburn 1993: chs. 8-9, 1998: ch.9).

It is still an open question to what extent quasi-realism is successful, and absolutists in particular tend to be unimpressed (see e.g. ShaferLandau 2003:ch.1; Huemer 2005:ch.2). Nevertheless, the quasi-realist program is clearly rich and promising enough to warrant an interest in its consequences. The most obvious, and intended, consequence of its success would of course be that noncognitivism becomes more plausible, as it would avoid the seemingly implausible metaphysical, epistemological and semantic commitments of absolutist cognitivist positions, while respecting the many similarities between morality and paradigmatically cognitive domains that seem to afford knowledge of objective facts. ${ }^{1}$

But our concern here is with a difficulty recognized by a number of authors, namely that the success of quasi-realism would undermine standard ways of understanding the difference between absolutism and non-

\footnotetext{
${ }^{1}$ Intriguingly, Street (2011) argues that quasi-realism will face epistemic problems inherent in taking moral facts to be entirely independent of our views about such facts. For criticism, see Vavova (2013).
} 
cognitivism (Wright 1985; Boghossian 1990; Divers and Miller 1994; Dworkin 1996; Rosen 1998; Dreier 2002; Gibbard 2003; Dreier 2004; Harcourt 2005; Street 2011). If successful, quasi-realism would let noncognitivists say that moral thinking ensues in moral beliefs that can be true or false depending on whether they correctly represent how things are, and whose truth-value is independent of whose beliefs they are, and further say that in moral disagreement, both parties cannot be correct. Employing similar explanatory strategies, strong relativists might try to adopt and adapt some of these explanations, defending a form of quasiabsolutism with reference to the practical function of moral thinking, discourse, and criticism (Björnsson and Finlay 2010; Björnsson 2013; cf. Wong 1984: 73; Finlay 2004). Traditionally, noncognitivists have of course also rejected more specific positive theses often associated with substantial forms of both absolutist and relativist cognitivism, denying that moral predicates come with analytic constraints substantial enough to provide truth-conditions for moral judgments, or that standard naturalist theories of reference determine the referents of moral predicates. But so have metaethical non-naturalists (Shafer-Landau 2003; Huemer 2005; Enoch 2011).

\section{Some Attempts to Retain the Old Distinctions}

Drawing on earlier proposals (O'Leary-Hawthorne and Price 1996; Fine 2001; Gibbard 2003), Jamie Dreier (2004) suggests that the real bone of contention between contemporary heirs of noncognitivism ("expressivists") and non-naturalist absolutist cognitivists ("realists") is this: realists, but not expressivists, think that fundamental explanations of the nature of our moral beliefs will make reference to moral facts. ${ }^{1}$ In a similar vein, James Lenman (2003) suggests that what distinguishes cognitivists from a quasi-realists is that the former takes moral statements to have truth-conditions irreducibly, rather than in virtue of their practical function. The proposals remain somewhat unclear in the absence of constraints on the relevant kind of explanation, and this difficulty is somewhat compounded by the fact that quasi-realists have argued that

\footnotetext{
${ }^{1}$ The explanation in question is not a causal explanation of why we form moral beliefs, but an account of the truth-makers of attributions of such beliefs. Realists can deny that moral facts are causally efficacious without thereby ceasing to be realists.
} 
they too can accommodate explanations of moral beliefs in terms of moral facts (e.g. Gibbard 2003:partIV). Of course, Gibbard (1990: ch.5; 2003:20) denies that "robust normative facts" play a role in explaining the nature of moral judgments, but the question here is what that denial amounts to - as Gibbard (2003:20) notes, this denial is shared by some non-naturalist realists. More importantly for our purposes, however, it is unclear why the difference in explanatory commitments matters for the possibility of a moral science. Such differences are of course theoretically interesting. But as long as moral truth is independent of the attitudes of individual judges, the correctness of judgments made by one party of a moral disagreement excludes the correctness of judgments made by another, and the correctness is determined by judge-independent facts, why does the order of explanation matter for the possibility of a collaborative enterprise aiming at the accumulation of correct answers to shared moral questions?

Another way to try drawing the relevant distinction is to understand belief in terms of the function or direction of fit of the act of moral judgment. This looks promising, because noncognitivist from Stevenson (1937) onwards have stressed that the function of moral claims is to produce a desire-like state, a state the psychological function of which is to bring about certain emotional states and behavior: disapproval of actions taken to be wrongful, say, and the avoidance of such actions. In other words, they have stressed that the function of moral thinking is to make the world fit the judgment (Stoljar 1993; Horwich 1994; O'LearyHawthorne and Price 1996).

Unfortunately, this is not enough in itself to make the distinction, since cognitivists can take moral beliefs to have exactly that function or direction of fit in addition to their cognitive function (cf. Dreier 2004: 33; Fine 2001:8). What needs to be added, it seems, is that noncognitivists take the act of moral judgment not to have the direction of fit of belief-forming mechanisms: moral beliefs are not to be adjusted to the world; the function of moral judgment is not to adequately map moral reality; and moral beliefs are not parts of such a map. The problem is that the quasi-realist strategies might seem to force the non-cognitivist to say that the act of moral judgment is to adjust moral beliefs to fit the facts. After all, if quasi-realism is successful, we are justified in saying that if it is a fact that wanton cruelty is wrong, then judgments to the 
effect that wanton cruelty is wrong are correct and judgments to the effect that it isn't wrong are incorrect; conversely if it is a fact that cruelty isn't wrong. In order to be correct, moral judgments need to be adjusted to fit the facts, just as do ordinary non-normative beliefs (cf. Sinclair 2005:255-56).

A possible way around this problem is to take the relevant kind of function to be a biological or more broadly etiological function. Such a function can be defined not in terms of when the judgments produced are correct or incorrect, but in terms of what the judgments have tracked such that this explains why, in general, we keep making the judgments. The noncognitivist would then deny that moral judgment have as their etiological function to track features of the world (cf. Ridge 2006b:6378 ), and the relativist could deny that your moral judgment and mine have as their function to keep track of the same features of the world. But there are problems with this suggestion too. One is that the proposal would be rejected both by some self-professed noncognitivists or expressivists who have thought that moral judgment has as its biological function to produce thoughts that correspond to certain (judge-relative) facts (e.g. Gibbard 1990:117-18), and by others, who are more sceptical about this biological claim, but nevertheless deny that its truth would undermine expressivism (Blackburn 1998: 121). ${ }^{1}$ Another problem is that at least non-naturalist cognitivists also want to deny that the content of moral judgments is determined by whatever function such judgments might be said to have from an etiological or biological point of view.

The last problem points to yet another way of understanding functions and direction of fit. Here is Neil Sinclair (2006:257-58):

Our beliefs determine the means we take to pursue our ends - this is why the truth conditions of a belief can be plausibly thought of as the condition under which the action it prompts would be successful in pursuit of those ends it is coupled with. Since the successful pursuit of ends depends on the state of the world, the best explanation of why beliefs affect the way we pursue our ends is that the system responsible for them is taken to produce representations whose content

\footnotetext{
${ }^{1}$ What Gibbard denies (1990: ch. 6) is that these facts are substantive normative facts, such that believing that they obtain is ipso facto to form a normative belief.
} 
matches the state of the world. That is, the function of beliefs ... is to have their contents match the state of the world.

I have already pointed out problems with an appeal to tracking based on etiology. But Sinclair's suggestion is designed to allow that the representations in question can be given the role of beliefs by agents because they take the system to produce representations whose content matches the state of the world. This might seem like a very sensible move. Whatever biological or etiological function something has, what matters seems to be what function we give it: perhaps the primary biological function of perception of human beauty is to select a healthy spouse, but human culture have given this perception and our reactions a much larger role, in many ways disconnected from that function. Similarly, even if moral judgments have as their etiological or biological function to track facts pertaining to how well a moral thought would promote beneficial cooperation, agents might rely on them for other reasons.

Unfortunately, this move to agent-selected function does not seem to help, if we assume that noncognitivists have successfully explained why we would take our moral beliefs to be correct representations, or to correspond to the facts, or match the state of the world. Given that assumption, it seems overwhelmingly likely that we do let our moral judgments govern our actions because we take our faculty of moral judgment to be fairly reliable in producing correct representations. For suppose that we had constantly found our judgments to be in conflict with our standards of correctness for such judgments, because the deliverance of our faculty of moral judgment were seriously unstable, or because we somehow kept being seriously mistaken about what our own moral beliefs are. Then we would very likely not be relying on our moral beliefs to guide our actions. If we wanted to help people do what is morally right, for example, we would not rely on our judgments of moral rightness, and if we wanted to do some good, we would not trust our judgments about what is good. So it seems that we do rely on our moral judgments in guiding our actions because we take our faculty of moral judgment to reliably produce correct moral beliefs.

In this section, I have briefly raised various problems for attempts at preserving the cognitivist-noncognitivist distinction. I do not presume that my discussion has been conclusive: there might well be ways of finessing these attempts to overcome the problems. However, instead of 
exploring these attempts further, I will suggest that we can sidestep all these difficulties if we put to one side the distinction between cognitivism and noncognitivism and focus on the distinction between, on the one hand, absolutism and weak relativism, and, on the other, noncognitivism and strong relativism. The trick is to spell out the sense in which a moral science is made possible by the former because, according to them, people who are trying to answer moral questions have a common goal, or are concerned with answering the same questions.

\section{Judgment-Internal Correctness Conditions}

Intuitively, absolutism makes room for what I have called a moral science because if we are all asking the same questions, then we can share the answers. (Weak relativism approximates the result by having large groups being concerned with the same question, or nearly the same question.) What I want to capture is the sense that only absolutism takes everyone who judges whether an act is morally wrong to be concerned with the same question.

The difficulty is that, assuming the success of quasi-realist and quasiabsolutist strategies, talk about "being concerned with the same question" can be understood even from a noncognitivist or relativist starting point. You and I can plausibly be said to be concerned with the same question when I would be correct in thinking that the act is wrong if and only if you would correct in thinking so, and incorrect in thinking that the act is wrong if and only if you would be. And, as outlined in section 2, noncognitivists or relativists can let us say this because they take assessments of whether the judgments of others are correct or incorrect to be based on whether they satisfy our standards for moral judgment.

What is striking about this quasi-absolutist move is that it lets us say that the correctness conditions of two moral judgments coincide on the mere ground that they involve the same non-cognitive attitude. It is on this ground that we can proceed to assess the correctness of the moral judgments of others by whatever standards we assess our own moral judgments, in effect projecting an external standard of correctness onto their judgments. My plan, then, is to recover the important metaethical distinctions with reference to judgment-internal - rather than projective or external - correctness conditions. So let me explain what these are. 
Start with the following trivial observation: human beings engage in a wide variety of goal-directed mental and physical activities. We try to win wars, have coffee, express our innermost feelings, remember a password, or hurt someone. Goal-directed activities come with their own success conditions and their own correctness conditions. Suppose that Jill wants to hurt Joe, and manages to do so by telling him that she has always seen him as a loser. We can judge her action as a mistake by various standards, but relative to the goal that defines her effort to hurt Joe, it is a success, and her way of trying to hurt Joe is a correct way. The action satisfies its internal success and correctness conditions.

Among goal-directed activities, we find acts of judgment: we try to determine whether British Marmite is tasty, whether Brussels is the capital of Belgium, whether increasing the number of troops will win the war, or whether it was wrong to go to war in the first place. In making such judgments, we are trying to get something right. Exactly how to best think about what we are trying to get right when making a judgment is debatable. In the first instance, it might seem that we should go by the agent's fundamental criteria for a correct judgment, the ones that we take to trump all others if there is a conflict. If there are no clear fundamental criteria, but rather a tangled cluster of criteria, we should perhaps go by whether the object judged has whatever property best fits this cluster well enough and better than other properties, or he property that makes best sense of the practice of relying on the concept. Alternatively, the requirement might be that the object should have whatever property the concept is counterfactually responsive to, or has as its etiological function to track. A fully worked out theory of moral judgment will take a stance on these issues, telling us what exactly determines internal success conditions to acts of judgment. But independently of what that account might say, my suggestion is that we should understand the distinction between absolutism and the other metaethical positions in terms of such judgment-internal correctness conditions, rather than in terms of truth conditions. Here is how it would let us define absolutism about a concept C:

ABSOLUTISM: For any object A, and any two acts of judgment, $\mathrm{J}$ and $\mathrm{J}$, about whether $\mathrm{A}$ is $\mathrm{C}$, if $\mathrm{J}$ would be internally correct (incorrect) if yielding the verdict that $\mathrm{A}$ is $\mathrm{C}$, then $\mathrm{J}$ ' would also be internally correct (incorrect) if yielding the verdict that $\mathrm{A}$ is $\mathrm{C}$. 
To illustrate: If you and I are both judging whether Brussels is the capital of Belgium, then if my judgment would be internally correct yielding the verdict that Brussels is (not) the capital of Belgium, then your judgment would be internally correct if yielding the same verdict: ABSOLUTISM holds for $\mathrm{C}=$ the capital of Belgium. By contrast, if you and I are both judging whether British Marmite is tasty and if my judgment that it is tasty is internally correct, that doesn't mean that your judgment that it is tasty would be internally correct: ABSOLUTISM does not hold for $\mathrm{C}=$ tasty, because you and I judge taste in relation to different standards, i.e. our different palates. ${ }^{1}$

In this context, the most important advantage of defining absolutism in terms of judgment-internal correctness conditions is that it provides a straightforward answer to the worry raised by the prospect of a successful quasi-realism, the worry articulated by Wright, Gibbard, Dreier and others. The crucial difference between absolutist cognitivism and a form of noncognitivism that lets us affirm the very sentences that used to define absolutism, is simply that the latter denies ABSOLUTISM about our various moral concepts.

This denial, I take it, is no less part of Gibbard's and Blackburn's views than it was part of Stevenson's. Noncognitivist analyses of moral judgments in terms of attitudes, decisions or the acceptance of norms or plans leave it conceptually open that two judges applying the same moral concept to the same action perform acts with different internal success and correctness conditions. Moreover, these analyses suggest no internal success conditions other than whatever ultimate criteria that moral judges employ in the application of moral concepts, criteria that seem to vary from judge to judge (cf. Fine 2001:23-4). Indeed, I suspect that it is at least in part because noncognitivists have thought that something like ABSOLUTISM is implausible for moral predicates that they have

\footnotetext{
${ }^{1}$ I am not denying that some tastiness-judgments have more intersubjective ambitions. However, I take it that most of our tastiness-judgments are different: we make our judgments knowing fully well that others might make different judgments, and without thinking that our resulting beliefs will map onto some standard independent of our own palate. The example is intended to involve judgments of this latter kind. For further illustration, see the case of nearby, in section 5.
} 
thought that moral disagreement often is best understood as disagreement in attitude rather than cognitive or factual disagreement. ${ }^{1}$

Redefining absolutism in terms of judgment-internal correctness conditions not only lets us uphold the distinction between cognitivist absolutism and quasi-realism or quasi-absolutism, but also preserves what was important about the distinction between absolutism and weak relativism, on the one hand, and noncognitivism and strong relativism, on the other. If absolutism or weak relativism were true about moral concepts, the internal correctness conditions of our moral judgments would be coordinated in just the way needed for a moral science. According to absolutism, everyone who asks what acts are wrong, and what societies just, etc. would be performing acts with the same internal success conditions, thus opening prospects for collaboration in achieving that success; according to weak relativism, the same would be true about large groups of people. Not so for noncognitivism or strong relativism: we would be voicing different concerns when asking moral questions, and common enquiries would have to be preceded by the establishment of common objectives for these efforts through a prior convergence of attitudes. This wouldn't necessarily be a less worthy task, but more akin to politics than a normative enquiry or a normative science.

Understanding absolutism in terms of judgment-internal correctness conditions also makes perfect sense of mainstream metaethical inquiry. For example, the search for conceptual rules for or platitudes about moral concepts seems entirely appropriate if such rules or platitudes are understood as our fundamental criteria for the application of these concepts in acts of judgment. Similarly, standard arguments for and against different metaethical positions are perfectly intelligible. Our sense that two people are in real disagreement when one thinks that an act is wrong and another thinks that it is right can certainly indicate that in thinking about the issue they are engaged in acts of judgment with the same goals, and thus support absolutism (Brink 1989:29-35; Smith 1994:345; Björnsson 2012: 372-6). This support is of course problematic if relativists and noncognitivists can explain this sense with reference to

\footnotetext{
${ }^{1}$ Blackburn (1998: ch.9) is concerned to reject of various forms of relativism, but nothing he says in his criticism of relativism contradicts our new characterization of absolutism, as its truth or falsity would have no direct implications of the sort Blackburn is concerned to reject.
} 
kinds of disagreement that do not presuppose a common goal of judgment, as they have tried to do (Gibbard 2003:268-87). Conversely, the deep and widespread disagreement that seems to plague normative theory and has been taken as evidence for noncognitivism or neighboring forms of relativism is well understood as prima facie evidence that we have different goals when we are trying to decide whether an act is wrong: we use different criteria, and disagree systematically about particular cases (Wong 1984; Blackburn 1984:168; Harman and Thomson 1996: 8-14; Loeb 1998; Tersman 2006; Björnsson 2012, 2013). This evidence, in turn, is problematic if it can be made plausible that there is a common goal behind these criteria and that disagreement is due to a variety of mistakes (Brink 1989: 197-210; Huemer 2005: ch.6).

If my proposal here is on the right track, quasi-realism can be what most have taken it to be: not a threat to the most important metaethical distinctions, but an attempt to show that various embedded moral claims as well as everyday talk and thinking about moral truth, facts, disagreement, and so forth are intelligible given noncognitivist (or strongly relativistic) starting-points. If successful, quasi-realism undermines objecttions to noncognitivism based on apparently cognitivist phenomena, and objections to both noncognitivism and strong relativism based on apparently absolutist phenomena. But it leaves noncognitivism and strong relativism as much of a threat to the idea of a moral science as it used to be. Convergence in moral belief would still depend not only on better methods to find correct answers to our questions, but also, crucially, on the convergence of these questions.

\section{Questions and Answers}

Question: Quasi-realists like to say that the function of moral judgment and moral discourse is to achieve coordination of attitudes. Doesn't that suggest that moral judgments have absolutist correctness conditions: they are correct if they are such as to achieve successful coordination (under suitable circumstances)? Reply: If they have, then for our purposes quasi-realism would indeed be a form of absolutism. But there is no reason to think that whatever correctness conditions are provided by that function would be the same for every moral judge. The function of moral judgments is not simply to coordinate attitudes in some judgeindependent way, but plausibly to coordinate attitudes in ways beneficial to the moral judge, and to determine with whom she coordinates. What 
counts as successful coordination of the relevant sort is thus likely relative to the moral judge (Gibbard 1990:117-18; Björnsson 2012:38283; cf. Wong 1984).

Question: Doesn't the quasi-realist story presuppose that judges are committed to an intersubjective standard of correctness for attitudes, applying equally to all moral judges? And doesn't that show that under quasi-realism, ABSOLUTISM is satisfied for moral concepts? Reply: There are numerous different possible intersubjective standards. To say that judges are committed to the intersubjectivity of standards of correctness because this is required for coordination is not to say that they are committed to the same intersubjective standard.

Question: According to quasi-realism, everyone who is judging whether an act is wrong is trying to decide whether it is wrong, and every moral judge thinks that she would be successful if and only if the act is either wrong and she judged that it is wrong, or the act isn't wrong and she judged that it isn't wrong. Why, then, isn't ABSOLUTISM satisfied for $\mathrm{C}=$ wrongness? Reply: Assume that we can naturally say that two judges are both trying to determine whether $\mathrm{A}$ is $\mathrm{C}$, and that each is thinking that she would be successful if and only if either $\mathrm{A}$ is $\mathrm{C}$ and she judges that it is, or A isn't $\mathrm{C}$ and she judges that it isn't. This doesn't show that if the first judge would be successful in judging that $\mathrm{A}$ is $\mathrm{C}$, the second would be successful in making the same judgment. For example, suppose that both Laura and Liz are in London, each trying to find out whether Regent's Park is nearby, and each thinking that she will be successful if and only if either Regent's Park is nearby and she judges that it is, or it isn't nearby and she judges that it isn't. It doesn't follow that if Laura would be successful in her endeavor if she concluded that Regent's Park is nearby, Liz would also be successful if she came to the same conclusion. For if Laura and Liz are at different locations, or have different amounts of time or means of transportation at their disposal, what areas they count as nearby might be quite different. Similarly, suppose that both Laura and Liz want to find out whether British Marmite is tasty. If Liz is successful in her endeavor by coming to think that Marmite is tasty, that doesn't mean that Laura would be successful in her endeavor if she came to think that Marmite is tasty: perhaps it is tasty for Liz, but not for Laura. 


\section{A Complication: The Pragmatics of Goal-Attribution}

Before closing, I want to mention what I take to be a more serious worry about the appeal to judgment-internal success conditions, a worry relating to the pragmatics of goal-attributions.

The basis for the worry is that our grounds for attributing judgmental goals to a moral judge might be conflicted. She might in effect lean on conflicting criteria for judgmental success, and what criteria she takes as overriding might vary with the circumstances; with whether she is considering the matter in abstract or concrete terms, say, or with the order in which she considers various considerations. She might also be conflicted about which way of considering the matter is the right way, leaning one way or the other depending on what considerations are brought up. Or she might express a consistent view about which criteria are overriding, but in practice nearly always relies on the other set. Moreover, her judgments might perhaps be seen as tracking either of two kinds of fact, depending on what one takes to be ideal or normal conditions for tracking. And perhaps considerations of interpretative charity points in different directions depending on how much weight is given to different aspects of rationality.

Perhaps grounds for attributing judgmental goals are conflicted in one or more of these ways for most of us. Suppose in addition that the constitutive rules of goal attribution fail to determine what weight to give to these conflicting grounds and so fail to determine what we should say that the goals are. On this view of goal attribution, related to Quine's view of the indeterminacy of translation, it could be a fundamentally pragmatic or political move in moral discourse to say that everyone who is deciding whether an act is wrong has the same goal, and will be successful under the same conditions. ${ }^{1}$ And if that were the case, the choice

\footnotetext{
${ }^{1}$ Compare what goes on when we say that, at heart, someone means well, even though some of her actions and intentions are malicious. Though she is disposed to do evil and endorse malice under some circumstances, she might very well also be disposed to do good and to reject malice under other circumstances. What dispositions should we take to show her innermost intentions, her fundamental nature, whether she means well at heart? That, it seems, could be a matter of what dispositions are best integrated with other dispositions, or most stable under normal or privileged circumstances. But it could also be a matter of what dispositions we have reasons to stress. Her friends are perhaps likely to stress one aspect, her enemies another, a moral reformer a third, a social engineer a fourth, and she might herself
} 
between absolutism, forms of relativism, and noncognitivism could be a fundamentally political choice, and one in which the quasi-realist might come down on the absolutist side, thus again eradicating the proposed distinction. ${ }^{1}$ After all, on standard noncognitivist or relativist accounts, we engage in moral discourse because it helps us coordinate our expectations and actions so as to be able to live together and cooperate. Coordination might be much helped by treating each other as having a common goal and working together to both clarify that goal, and to find ways of achieving it.

This, then, is the worry that I want to address very briefly before closing: the politics of goal attribution could give us strong enough reasons to endorse ABSOLUTISM for moral predicates on grounds that seem perfectly acceptable given a picture of moral thinking that noncognitivists and relativists have been happy to endorse.

Suppose that this worry is well founded. If so, we might try to distinguish absolutism from its rivals with reference to the grounds on which ABSOLUTISM is accepted. Metaethicists, in particular those in the noncognitivist and relativist traditions, have been concerned mainly with explaining various puzzling aspects of moral thinking and moral discourse, in part guided by a wish to let us participate in normative discussion with a clearer grasp of what is going on (cf. Wong 1984: ch. 8). Their concern has not been to paint the most agreeable or pragmatically useful picture possible, but the one that is most revealing and accurate. For that reason, we might understand absolutism as the claim that in contexts where we are primarily interested in politically disinterested explanation, it is correct to ascribe the same judgment-internal success conditions to everyone who is judging whether something is $\mathrm{C}$.

Much more can be said about taking absolutism and its rivals as explanatory claims. It is not clear that shared explanatory standards are determinate enough to settle the issue here in all cases, nor entirely clear that explanatory virtues can be entirely independent from the very practical concerns that noncognitivists and relativists are eager to stress. But

stress different aspects in different situations. But the mere recognition of her various dispositions, unguided by a definite interest might point in no definite direction. ${ }^{1}$ Complicating the picture somewhat is the possibility that the attribution of judgments of moral wrongness might also be a pragmatic affair (cf. Björnsson and McPherson 2013). 
understanding the metaethical positions as claims with a primarily explanatory import offers a perspective that should appeal to those who take a pragmatic view of goal-attribution and for whom the worry raised in this section will seem especially pressing. For those who think that the pragmatics of goal-attribution has little to do with what the judgmental goals we actually have, ABSOLUTISM itself would seem to capture what absolutism was all about.

\section{References}

Björnsson, Gunnar (2001). "Why Emotivists Love Inconsistency", Philosophical Studies, 104:81-108.

Björnsson, Gunnar (2012). "Do 'Objectivist' Features of Moral Discourse and Thinking Support Moral Objectivism?”. The Journal of Ethics, 16:367-93.

Björnsson, Gunnar (2013). "The Implausibility of Metaethical Absolutism", manuscript.

Björnsson, Gunnar, and Almér, Alexander (2010). "The Pragmatics of Insensitive Assessments: Understanding The Relativity of Assessments of Judgments of Personal Taste, Epistemic Modals, and More", in B. H. Partee, M. Glanzberg \& J. Skilters (eds.), Formal Semantics and Pragmatics. Discourse, Context and Models, Manhattan, KS: New Prairie Press, 1-45.

Björnsson, Gunnar, and Finlay, Stephen (2010). "Defending Metaethical Contextualism", Ethics, 121:7-36.

Björnsson, Gunnar, and McPherson, Tristram (2013). "Moral Attitudes for Non-Cognitivists: Solving the Specification Problem", forthcoming in Mind.

Blackburn, Simon (1984). Spreading the Word, Oxford: Oxford University Press.

Blackburn, Simon (1993). Essays in Quasi-Realism, Oxford: Oxford University Press.

Blackburn, Simon (1998). Ruling Passions, Oxford: Oxford University Press.

Boyd, Richard (1988) "How to Be a Moral Realist", in Geoffrey SayreMcCord (ed.), Essays on Moral Realism, Ithaca, N.Y.: Cornell University Press, 181-228. 
Brink, David O. (1989). Moral Realism and the Foundations of Ethics, Cambridge: Cambridge University Press.

Dreier, James (2004). "Meta-Ethics and the Problem of Creeping Minimalism", Philosophical Perspectives, 18:23-44.

Dreier, James (2009) "Relativism (and Expressivism) and the Problem of Disagreement", Philosophical Perspectives, 23:79-110.

Dworkin, Ronald (1996). “Objectivity and Truth: You'd Better Believe It", Philosophy and Public Affairs, 25:87-139.

Enoch, David (2011). Taking Morality Seriously, Oxford: Oxford University Press.

Fine, Kit (2001). "The Question of Realism", Philosopher's Imprint, 1: $1-30$.

Finlay, Stephen (2004). "The Conversational Practicality of Value Judgment", The Journal of Ethics, 8:205-23.

Gibbard, Allan (1990). Wise Choices, Apt Feelings, Cambridge, MA: Harvard University Press.

Gibbard, Allan (2003). Thinking How to Live, Cambridge, Mass.: Harvard University Press.

Goodwin, Geoffrey P. and Darley, John M. (2008). "The psychology of metaethics: Exploring objectivism", Cognition, 106:1339-66.

Hare, Richard M. (1981). Moral Thinking, Oxford: Oxford University Press.

Harman, Gilbert and Thomson, Judith Jarvis (1996). Moral Relativism and Moral Objectivity, Oxford: Blackwell.

Horgan, Terence and Timmons, Mark (2004). "Expressivism, Yes! Relativism, No!", in Russ Shafer-Landau (ed.), Oxford Studies in Metaethics, Vol. 1, Oxford: Clarendon Press, 73-98.

Horwich, Paul (1994). "The Essence of Expressivism”, Analysis, 54: 1920.

Huemer, Michael (2005). Ethical Intuitionism, Basingstoke: Palgrave Macmillan.

Johansson, Ingvar (1994) Is Ought?, manuscript

Joyce, Richard (2002). "Expressivism and Motivation Internalism", Analysis, 62:336-44. 
Lenman, James (2003). "Disciplined Syntacticism and Moral Expressivism". Philosophy and Phenomenological Research, 66:32-57.

Lenman, James (2007). "Expressivism and Epistemology: What Is Moral Inquiry?", Aristotelian Society Supplementary Volume, 81:6381.

Loeb, Don (1998). "Moral Realism and the Argument from Disagreement", Philosophical Studies, 90:281-303.

O'Leary-Hawthorne, John, and Price, Huw (1996). "How to Stand up for Non-Cognitivists", Australasian Journal of Philosophy, 74:275-92.

Ridge, Michael (2006a). "Ecumenical Expressivism: Finessing Frege", Ethics, 116:302-36.

Ridge, Michael (2006b). "Saving the Ethical Appearances", Mind, 115:633-49.

Ridge, Michael (2006c). "Sincerity and Expressivism", Philosophical Studies, 131: 487-510.

Schroeder, Mark (2008a). "Expression for Expressivists", Philosophy and Phenomenological Research, 76:86-116.

Schroeder, Mark (2008b). Being For, Oxford: Oxford University Press.

Schroeder, Mark (2009). "Hybrid Expressivism: Virtues and Vices", Ethics, 119:257-309.

Shafer-Landau, Russ (2003). Moral Realism: A Defence, Oxford: Oxford University Press.

Sinclair, Neil (2006). "The Moral Belief Problem", Ratio (new series), 19:249-60.

Sinclair, Neil (2011). "Moral Expressivism and Sentential Negation", Philosophical Studies, 152:385-411.

Smith, Michael (1994). The Moral Problem, Oxford: Basil Blackwell.

Stevenson, Charles L. (1937). "The Emotive Meaning of Ethical Terms". Mind, 46:14-31.

Stoljar, Daniel (1993). "Emotivism and Truth Conditions", Philosophical Studies, 70:81-101.

Street, Sharon (2011). "Mind-Independence without the Mystery: Why Quasi-Realists Can't Have it Both Ways", in Russ Shafer-Landau 
(ed.), Oxford Studies in Metaethics, Vol 6, Oxford: Oxford University Press, 1-32.

Tersman, Folke (2006). Moral Disagreement, Cambridge University Press.

Timmons, Mark (1999). Morality without Foundations: A Defense of Ethical Contextualism, Oxford University Press.

Vavova, Katia (2013). "Debunking Evolutionary Debunking”, provisionally forthcoming in Oxford Studies in Metaethics.

Wong, David (1984). Moral Relativity. Berkeley: University of California Press. 